\title{
Recovery of Waste Heat in Diesel Engine Coolant for Air Conditioning
}

\author{
Hanzhi Wang ${ }^{1,2, a}$, Huashan $\mathrm{Li}^{1,2, b}$, Lingbao Wang ${ }^{1,2, \mathrm{c}}$ and Xianbiao $\mathrm{Bu}^{1, \mathrm{~d}}$ \\ ${ }^{1}$ CAS Key Laboratory of Renewable Energy, Guangzhou Institute of Energy Conversion, Chinese \\ Academy of Sciences, Guangzhou 510640, China \\ ${ }^{2}$ University of Chinese Academy of Sciences, Beijing 100049, China \\ awanghz@ms.giec.ac.cn, 'blihs@ms.giec.ac.cn, cwanglb@ms.giec.ac.cn, \\ dcorresponding author: (buxb@ms.giec.ac.cn)
}

Keywords: Waste heat recovery, Engine coolant, Organic Rankine cycle, Vapor compression refrigeration cycle

Abstract: In this paper, an organic Rankine cycle driven vapor compression refrigeration (ORC-VCR) system for heavy-duty trucks' cab and sleeper air conditioning using the waste heat in engine coolant is analyzed. R245fa and R134a are, respectively, selected as working fluids for the power and cooling cycles. Assuming $5.0 \mathrm{~kW}$ cooling capacity needed, the study shows that under the typical working conditions, the overall coefficient of performance (COP) and heat requirement of the ORC-VCR system are about 0.224 and $22.343 \mathrm{~kW}$, respectively. The effects of operating parameters on the system performance are also discussed.

\section{Introduction}

In recent years, increased attention has been focused on heavy-duty trucks due to their significantly higher emission factor and travel mileage relative to gasoline cars [1]. It is known that the thermal efficiency of diesel engine in these trucks is very low; only about $30 \%$ of the fuel energy used is transformed into mechanical work, and the remaining is all wasted. Besides, the heavy-duty trucks have considerable cooling requirement in the cab and sleeper [2], which is provided by a vapor compression refrigeration (VCR) system that conventionally powered by the engine and thus has a significant impact on the fuel consumption.

Thermally activated cooling technologies have been accepted as a promising alternative to the VCR system for reducing the fuel consumption and emissions in automobiles. In this field, absorption and adsorption cooling technologies are often related $[3,4]$, but it should be mentioned that the practical application has rarely been done. This is mainly due to that the limited free space in automobiles hardly accommodates the bulky heat exchangers as well as the relatively large weight involved. The organic Rankine cycle (ORC) is well known as a method for recovering and utilizing low-grade thermal energy. Due to the great advantage of the ORC, some innovative concepts coupling the ORC have been developed [5]. One example is an organic Rankine cycle driven refrigeration system, which is a combination of an ORC and a VCR cycle [6], denoted as the ORC-VCR system hereafter. Comparing with the sorption cooling systems, the ORC-VCR has smaller size, easier control and quick response giving a short time lag to reach the full cooling capacity [7]. These features make this technology can be well accepted by the automobiles for air conditioning.

In addition, current works related to the ORC for recovering the waste heat of automobiles mainly focus on the exhaust gases. Although these configurations are effective, the heat exchange between gas and liquid, coupled with the need to minimize the exhaust gas pressure drop involved, leads to that the heat exchanger are bulky, expensive and difficult to install in automobiles [8]. Moreover, the engine speed fluctuations could complicate the control process in recovering the exhaust waste heat [9]. Comparatively, a system utilizing the waste heat in the engine coolant, which is normally dissipated to the environments by a radiator, is an attractive alternative since no gas-to-liquid heat exchanger is required [8]. 
However, there are few researches on the ORC-VCR system in heavy-duty vehicles, especially driven by only the waste heat in the engine coolant. The main objective of the present paper is to investigate the potential of an ORC-VCR system for air conditioning the heavy-duty trucks' cab and sleeper using the waste heat in the engine coolant. R245fa and R134a are selected as working fluids for the power and cooling cycles, respectively. The effects of operating parameters on the system performance are also discussed.

\section{System description}

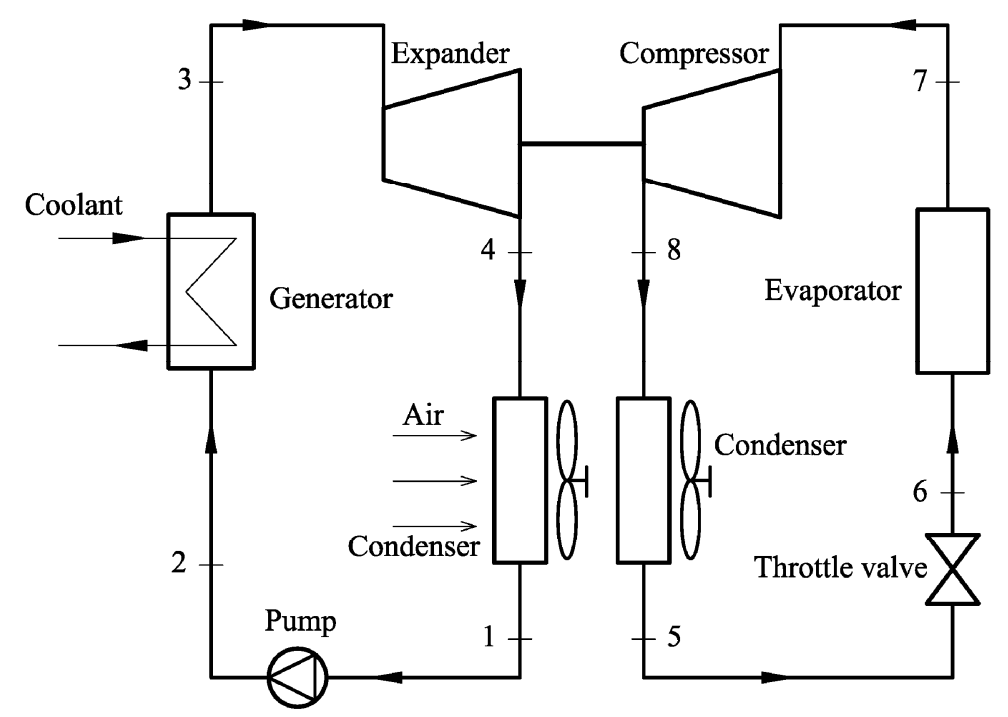

Fig. 1 Schematic diagram of ORC-VCR system

The schematic diagram of the ORC-VCR system investigated is presented in Fig. 1. This system consists of two sub-cycles, i.e. the ORC identified as 1-2-3-4-1 and the VCR cycle as 5-6-7-8-5. In the ORC, the condensed R245fa is pressurized by the pump and enters the generator where it is heated by the engine coolant. Then the vapor of R245fa produced in the generator flows into the expander which produces mechanical work to drive the pump in the ORC and the compressor in the VCR cycle. Subsequently, R245fa returns to the condenser and the ORC is completed. In the VCR cycle, the liquid R134a out of the condenser goes through the throttle valve and enters the evaporator where the low pressure and low temperature R134a vaporizes and cools the air circulated in the truck's cab and sleeper. In the sequence, the vapor of R134a is sucked into the compressor where it is pressurized and then discharged into the condenser to complete the VCR cycle.

\section{Thermodynamic analysis}

For simplicity, some assumptions are made as follows: (1) steady-state flow in each component is considered; (2) the heat and friction losses in the system are negligible; (3) the ORC-VCR system is air-cooled; (4) the working fluids leaving the generator, condensers and evaporator are assumed to be saturated; (5) the generation temperature is lower than the engine coolant temperature by $8{ }^{\circ} \mathrm{C} ;(6)$ the ORC and VCR cycles have same condensing temperature, which is higher than the ambient air temperature by $15^{\circ} \mathrm{C}$.

According to the state points defined in Fig. 1, the shaft work delivered by the expander $\left(\mathrm{W}_{\text {exp }}, \mathrm{kW}\right)$ can be calculated by Eq. (1)

$$
W_{\text {exp }}=m_{\text {ORC }}\left(h_{3}-h_{4 \mathrm{~s}}\right) \eta_{\exp } \text {. }
$$

where $m_{\mathrm{ORC}}$ is the mass flow rate in the $\mathrm{ORC}, \mathrm{kg} / \mathrm{s} ; h_{3}$ is the specific enthalpy at the generator outlet, $\mathrm{kJ} / \mathrm{kg} ; h_{4 \mathrm{~s}}$ is the specific enthalpy at the expander outlet based on isentropic process, $\mathrm{kJ} / \mathrm{kg} ; \eta_{\exp }$ is the expander isentropic efficiency.

The work required by the pump ( $\left.\mathrm{W}_{\text {comp }}, \mathrm{kW}\right)$ in the ORC and the compressor $\left(\mathrm{W}_{\text {comp }}, \mathrm{kW}\right)$ in the VCR cycle is determined as follows 


$$
\begin{aligned}
& W_{\text {pump }}=m_{\mathrm{ORC}}\left(h_{2 \mathrm{~s}}-h_{1}\right) / \eta_{\text {pump }} . \\
& W_{\text {comp }}=m_{\mathrm{VCR}}\left(h_{8 \mathrm{~s}}-h_{7}\right) / \eta_{\text {comp }} .
\end{aligned}
$$

where $h_{2 \mathrm{~s}}$ is the specific enthalpy at the pump outlet based on isentropic process, $\mathrm{kJ} / \mathrm{kg} ; h_{1}$ is the specific enthalpy at the outlet of the condenser in the ORC, $\mathrm{kJ} / \mathrm{kg} ; \eta_{\text {pump }}$ is the pump isentropic efficiency; $m_{\mathrm{VCR}}$ is the mass flow rate in the VCR cycle, $\mathrm{kg} / \mathrm{s} ; h_{8 \mathrm{~s}}$ is the specific enthalpy at the compressor outlet based on isentropic process, $\mathrm{kJ} / \mathrm{kg} ; h_{7}$ is the specific enthalpy at the evaporator outlet, $\mathrm{kJ} / \mathrm{kg}$.

Assuming a given cooling capacity $\left(\mathrm{Q}_{\text {evap }}, \mathrm{kW}\right)$, the mass flow rate in the VCR cycle, $\mathrm{m}_{\mathrm{VCR}}$, can be determined as

$$
m_{\mathrm{vCR}}=Q_{\text {evap }} /\left(h_{7}-h_{6}\right) \text {. }
$$

where $h_{6}$ is the specific enthalpy at the throttle valve outlet, $\mathrm{kJ} / \mathrm{kg}$.

Then, assuming that the mechanical work delivered by the expander is used to drive the pump in the ORC and the compressor in the VCR cycle, the mass flow rate in the ORC is calculated as

$m_{\text {ORC }}=W_{\text {comp }} /\left[\left(h_{3}-h_{4 \mathrm{~s}}\right) \eta_{\exp }-\left(h_{2 \mathrm{~s}}-h_{1}\right) / \eta_{\text {pump }}\right]$.

Accordingly, the heat requirement in the generator $\left(\mathrm{Q}_{\mathrm{gen}}, \mathrm{kW}\right)$ for producing the given cooling capacity is defined as

$Q_{\text {gen }}=m_{\text {ORC }}\left(h_{3}-h_{2}\right)$.

where $h_{2}$ is the specific enthalpy at the pump outlet, $\mathrm{kJ} / \mathrm{kg}$.

The thermal efficiency of the ORC $\left(\eta_{\mathrm{ORC}}\right)$ is defined as

$\eta_{\mathrm{ORC}}=\left(W_{\text {exp }}-W_{\text {pump }}\right) / Q_{\text {gen }}$.

The coefficient of performance $(\mathrm{COP})$ of the VCR cycle $\left(\mathrm{COP}_{\mathrm{VCR}}\right)$ is expressed as $\mathrm{COP}_{\mathrm{VCR}}=Q_{\text {evap }} / W_{\text {comp }}$.

Hence, the overall COP of the ORC-VCR system $\left(\mathrm{COP}_{\text {oval }}\right)$ can be calculated as

$$
\mathrm{COP}_{\mathrm{oval}}=\eta_{\mathrm{ORC}} \mathrm{COP}_{\mathrm{vCR}} \text {. }
$$

\section{Results and discussion}

The analysis in this paper starts with assuming a cooling capacity of $5 \mathrm{~kW}$ for chilling the heavy-duty truck's cab and sleeper. In the following analysis, the typical values of coolant temperature $\left(T_{\text {clnt }}\right)$, ambient air temperature ( $\left.T_{\text {air }}\right)$, evaporation temperature $\left(T_{\text {evap }}\right)$ are set as 90,35 and $5{ }^{\circ} \mathrm{C}$, respectively. These values are constant except the parameter whose effect is investigated varies. Also, the isentropic efficiencies of the expander, compressor and pump are fixed at 0.80, 0.75 and 0.75 , respectively.

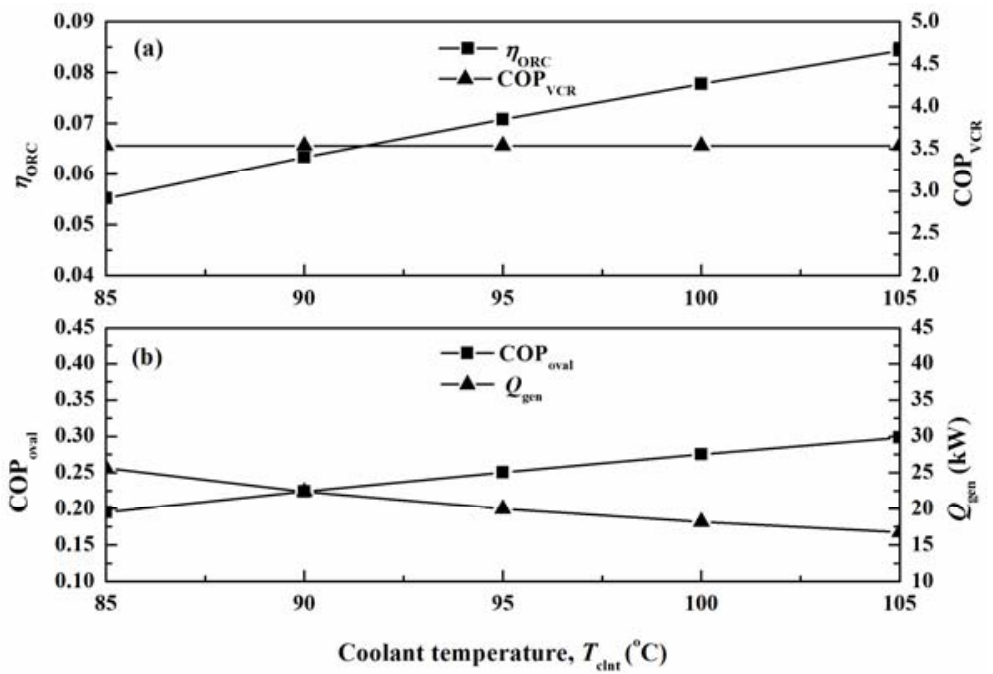

Fig. 2 Effects of coolant temperature on (a) $\eta_{\mathrm{ORC}}$ and $\mathrm{COP}_{\mathrm{VCR}}$ and (b) $\mathrm{COP}_{\text {oval }}$ and $Q_{\text {gen }}$ 
Fig. 2a shows the effects of the coolant temperature on the thermal efficiency of the ORC and the COP of the VCR cycle. It is found that with the increase in the coolant temperature, the $\eta_{\mathrm{ORC}}$ increases gradually from 0.055 to 0.084 while the $\mathrm{COP}_{\mathrm{VCR}}$ keeps constant at 3.537. So, as shown in Fig. 2b, the overall COP of the ORC-VCR system increases with the increased coolant temperature, which leads to a decrease in the heat requirement. With the coolant temperature out of the heavy-duty engine at 85 and $105{ }^{\circ} \mathrm{C}$, the $\mathrm{COP}_{\text {oval }}$ of the ORC-VCR system is about 0.195 and 0.298 , respectively, and the $Q_{\text {gen }}$ reaches 25.621 and $16.769 \mathrm{~kW}$, respectively. It is worthwhile to mention that the coolant temperature slightly higher than that of water boiling point $\left(100{ }^{\circ} \mathrm{C}\right.$ at $\left.1 \mathrm{~atm}\right)$ can be expected with ethylene glycol-water mixture introduced [10]. Although the thermal efficiency of the ORC-VCR system is generally lower than the absorption cooling system at equivalent temperature level, the maximum amount of the heat requirement in the generator under the working conditions considered can be easily covered by the coolant waste heat in the heavy-duty trucks under normal driving conditions [11].

Under air-cooled conditions, the condensing temperature of the ORC-VCR system is determined by ambient air temperature, which have effects on both the power and cooling cycles. Fig. 3a depicts that the increased ambient air temperature causes both the $\eta_{\mathrm{ORC}}$ and $\mathrm{COP}_{\mathrm{VCR}}$ to decrease. The ambient air temperature increasing from 25 to $45{ }^{\circ} \mathrm{C}$ leads to that the $\eta_{\mathrm{ORC}}$ and $\mathrm{COP}_{\mathrm{VCR}}$ approximately decrease by $45 \%$ and $47 \%$, respectively, which means that the effect of the condensing temperature on the VCR cycle is more pronounced as comparing with that of on the ORC.

Also, as expected, the overall COP of the ORC-VCR system decreases with the ambient air temperature increase, and consequently an increase in the heat requirement for producing the given cooling capacity is found. These results are illustrated in Fig. $3 \mathrm{~b}$. When the ambient air temperature reaches its maximum of $45{ }^{\circ} \mathrm{C}$ in this study, the $\mathrm{COP}_{\text {oval }}$ and $Q_{\mathrm{gen}}$ of the ORC-VCR system reduce to 0.118 and $42.535 \mathrm{~kW}$ or so, respectively. Fortunately, the days with the highest ambient air temperature above $45^{\circ} \mathrm{C}$ during air conditioning seasons are scarce in China, and the daily average ambient air temperature is often below $35{ }^{\circ} \mathrm{C}$ [12]. In the typical case, the performance of the ORC-VCR system approximately doubles comparing with the extreme ambient air conditions.

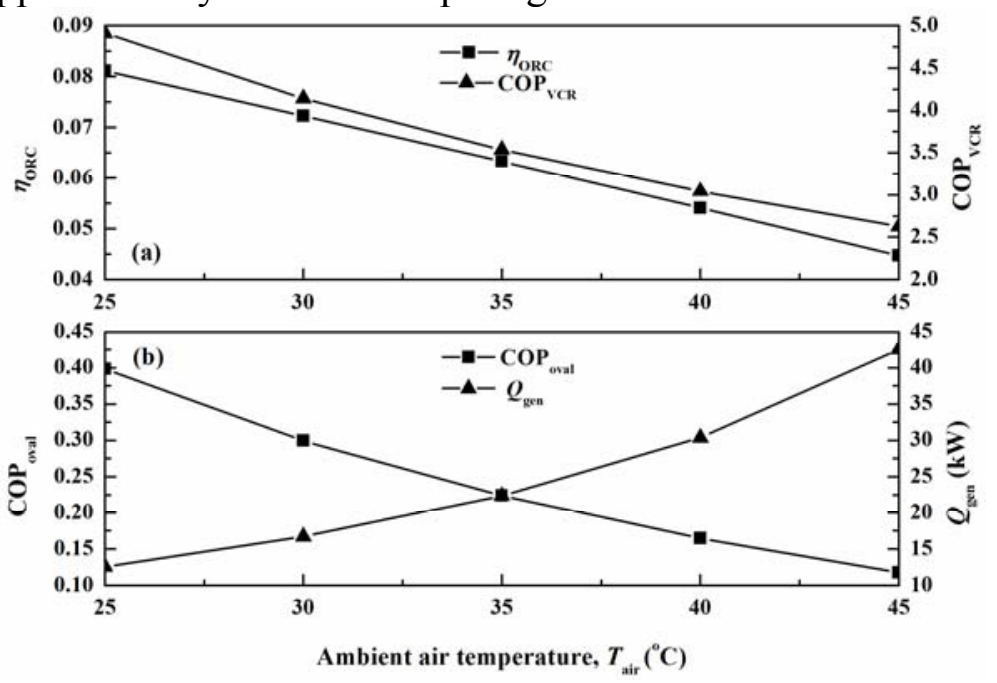

Fig. 3 Effects of ambient air temperature on (a) $\eta_{\mathrm{ORC}}$ and $\mathrm{COP}_{\mathrm{VCR}}$ and (b) $\mathrm{COP}_{\text {oval }}$ and $Q_{\text {gen }}$

Fig. 4a shows that when the evaporation temperature increases, the thermal efficiency of the ORC keeps constant while the COP of the VCR cycle increases. With the evaporation temperature increasing from 0 to $7{ }^{\circ} \mathrm{C}$, the $\mathrm{COP}_{\mathrm{VCR}}$ ranges from 3.044 to 3.767. As a result, Fig. $4 \mathrm{~b}$ shows that the overall COP of the ORC-VCR system increases with the evaporation temperature increasing, and the heat requirement in the generator decreases. While the evaporation temperature at the typical value, the $\mathrm{COP}_{\text {oval }}$ and $Q_{\text {gen }}$ of the ORC-VCR system are about 0.224 and $22.343 \mathrm{~kW}$, respectively. With the evaporation temperature goes up to $7{ }^{\circ} \mathrm{C}$, the $\mathrm{COP}_{\text {oval }}$ of the ORC-VCR system peaks up to 0.238 and the corresponding $Q_{\text {gen }}$ drops to $20.978 \mathrm{~kW}$. 

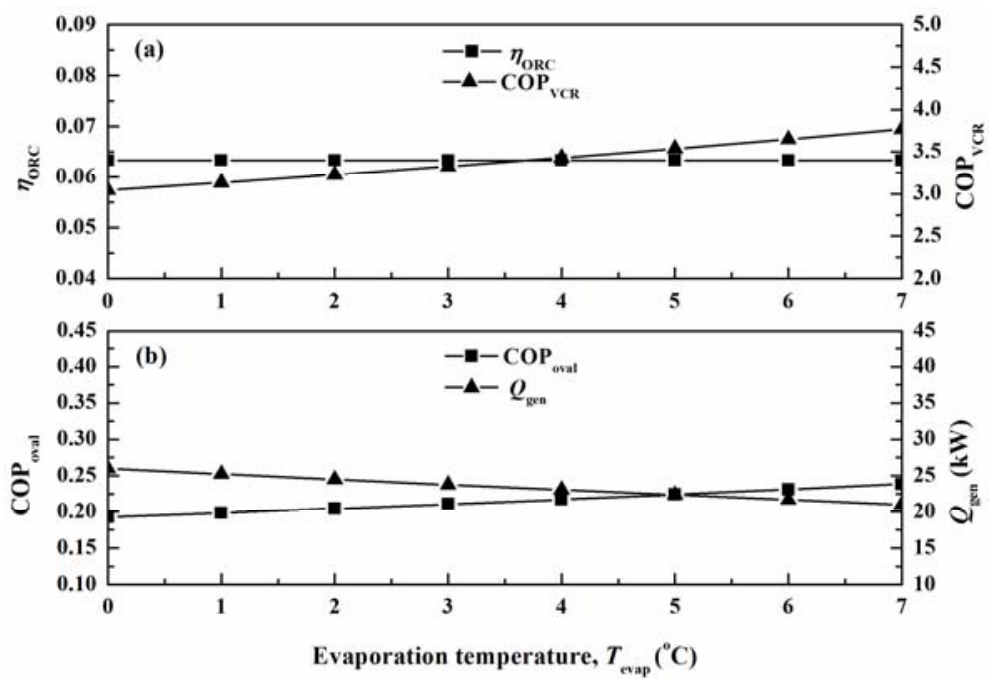

Fig. 4 Effects of evaporation temperature on (a) $\eta_{\mathrm{ORC}}$ and $\mathrm{COP}_{\mathrm{VCR}}$ and (b) $\mathrm{COP}_{\text {oval }}$ and $Q_{\text {gen }}$

\section{Conclusions}

The present paper investigates the ORC-VCR system for heavy-duty truck air conditioning using the waste heat in engine coolant. With R245fa as working fluid in the ORC and R134a in the VCR cycle and assuming $5.0 \mathrm{~kW}$ cooling capacity needed, the study shows that under the typical working conditions considered, i.e. $T_{\text {clnt }}=90{ }^{\circ} \mathrm{C}, T_{\text {air }}=35{ }^{\circ} \mathrm{C}, T_{\text {evap }}=5{ }^{\circ} \mathrm{C}, \eta_{\text {exp }}=0.80, \eta_{\text {comp }}=0.75$ and $\eta_{\text {pump }}=0.75$, the overall COP and heat requirement of the ORC-VCR system are about 0.224 and $22.343 \mathrm{~kW}$, respectively. The worst case with the lowest $\mathrm{COP}_{\text {oval }}$ of 0.118 and the greatest $Q_{\text {gen }}$ of $42.535 \mathrm{~kW}$ occurs when the ambient air temperature reaches $45{ }^{\circ} \mathrm{C}$. In addition, the performance of the ORC-VCR system can be improved by increasing the coolant temperature and evaporation temperature. Also, in non-extreme ambient conditions, the system performance could be relatively better.

\section{Acknowledgements}

This work is financially supported by the Pearl River S\&T Nova Program of Guangzhou (No. 2014J2200079), National Natural Science Foundation of China (No. 51106161) and Natural Science Foundation of Guangdong Province (2015A030313714).

\section{References}

[1] Y. Wu, S.J. Zhang, M.L. Li, Y.S. Ge, J.W. Shu, Y. Zhou, Y.Y. Xu, J.N. Hu, H. Liu, L.X. Fu, K.B. He, and J M. Hao: Atmospheric Chemistry and Physics, Vol. 12 (2012) No.19, p.18565.

[2] Y. Zhong, K.L. Wert and T. Fang: International Refrigeration and Air Conditioning Conference (Indiana, United States, July 12-15, 2010). p.1100.

[3] R.E. Critoph, S.J. Metcalf and Z. Tamainot-Telto: Heat Transfer Engineering, Vol. 31 (2010) No.11, p.950.

[4] A.A. Manzela, S.M. Hanriot, L. Cabezas-Gómez and J.R. Sodré: Applied energy, Vol. 87 (2010) No.4, p.1141.

[5] B.F. Tchanche, G. Lambrinos, A. Frangoudakis and G. Papadakis: Renewable and Sustainable Energy Reviews, Vol. 15 (2011) No.8, p.3963.

[6] M. Dubey, S.P.S. Rajput, P.K. Nag and R.D. Misra: Proceedings of the Institution of Mechanical Engineers, Part A: Journal of Power and Energy, Vol. 224 (2010) No.6, p.749. 
[7] J. Jeong and Y.T. Kang: International journal of refrigeration, Vol. 27 (2004) No.1, p.33.

[8] V. Antohi: U.S. Patent 5896747. (1999).

[9] I.C. Sprouse and C. Depcik: Applied Thermal Engineering, Vol. 51 (2013) No.1, p.711.

[10] H. Teng, G. Regner and C. Cowland: Commercial Vehicle Engineering Congress \& Exhibition. (Chicago, United States, October 31-November 2, 2006). Vol. 1, p.3522.

[11] V. Dolz, R. Novella, A. García and J. Sánchez: Applied Thermal Engineering, Vol. 36 (2012), p.269.

[12] S.M. Xu, F.S. Liu and J.B. Li: Journal of Thermal Science and Technology, Vol. 11 (2012) No.2, p.148. 